\title{
Smiles, Bid-ask Spreads and Option Pricing
}

\section{Ignacio Peña}

Universidad Carlos III de Madrid, Spain

e-mail: ypenya@eco.uc3m.es

\section{Gonzalo Rubio}

Universidad del País Vasco, Bilbao, Spain

e-mail: jepruirg@bs.ehu.es

\section{and Gregorio Serna*}

Universidad de Castilla La Mancha, Toledo, Spain

e-mail: gserna@emp.uc3m.es

\begin{abstract}
Given the evidence provided by Longstaff (1995), and Peña, Rubio and Serna (1999) a serious candidate to explain the pronounced pattern of volatility estimates across exercise prices might be related to liquidity costs. Using all calls and puts transacted between 16:00 and 16:45 on the Spanish IBEX-35 index futures from January 1994 to October 1998 we extend previous papers to study the influence of liquidity costs, as proxied by the relative bid-ask spread, on the pricing of options. Surprisingly, alternative parametric option pricing models incorporating the bid-ask spread seem to perform poorly relative to Black-Scholes.
\end{abstract}

Keywords: smiles; bid-ask spread; implied volatility function; option pricing.

JEL classification: $G 12, G 13$.

\section{Introduction}

Given the Black-Scholes (1973) (BS henceforth) assumptions, all option prices on the same underlying security with the same expiration date but with different exercise prices should have the same implied volatility. However, after the October $1987 \mathrm{crash}$,

\footnotetext{
*We have received valuable comments from Bernard Dumas, Ignacio Olmeda, Angel León and two anonymous referees, as well as seminar participants at the II Encuentro de Economía Aplicada, Zaragoza, 8th Annual Meeting of the European Financial Management Association, Paris, and III Foro de Segovia-Finanzas. Gonzalo Rubio and Ignacio Peña acknowledge the financial support provided by Dirección Interministerial Científica y Técnica (DGICYT) grants PB97-0621 and PB95-0298 respectively. Gregorio Serna would also like to acknowledge the financial support provided by Fundación Caja de Madrid.
} 
the implied volatility computed from options on stock indexes in the US market inferred from the BS formula appears to be different across exercise prices. This well known volatility smile suggests that the BS formula tends to misprice deep in-themoney and deep out-of-the-money options. In fact, as pointed out by Rubinstein (1994), Ait-Sahalia and Lo (1998) and Dumas et al. (1998) (DFW henceforth), implied volatilities of the S\&P 500 options decrease monotonically as the exercise price becomes higher relative to the current level of the underlying asset. On the other hand, Taylor and $\mathrm{Xu}$ (1994) show that currency options tend to present a much more pronounced smile. Similar patterns of implied volatilities across exercise prices are found by Peña et al. (1999) (PRS henceforth) in the Spanish options market. Moreover, Bakshi et al. (1997), and Fiorentini et al. (1998) report smile shapes for the (implied) instantaneous volatility under stochastic volatility and jump-diffusion option pricing models.

There have been various attempts to deal with this apparent failure of the BS valuation model. In principle, as explained by Das and Sundaram (1999) and others, the existence of the smile may be attributed to the well known presence of excess kurtosis in the return distributions of the underlying assets. It is clear that excess kurtosis makes extreme observations more likely than in the BS case. This increases the value of out-of-the-money and in-the-money options relative to at-the-money options, creating the smile. However, at least in the US market, the pattern shown by data contains a clear asymmetry in the shape of the smile. This may be due to the presence of skewness in the distribution which has the effect of accentuating just one side of the smile.

Given this evidence, extensions to the BS model that exhibit excess kurtosis and skewness have been proposed in recent years along two lines of research: jumpdiffusion models with a Poisson-driven jump process, and the stochastic volatility framework are the two key developments in the theoretical option pricing literature.

Unfortunately, however, the empirical evidence regarding these new models is quite disappointing. Bates (1996), and Bakshi et al. (1997) reject the jump-diffusion option pricing model on both currency options and equity options respectively. The stochastic volatility model proposed by Heston (1993) is rejected by Bakshi et al. (1997), and Chernov and Ghysels (1998) for options written on S\&P 500 index. Fiorentini et al. (1998) reject the same model for equity options on the Spanish IBEX-35 index and argue that the ultimate reasons behind the performance failure of Heston's model are closely related to the time-varying skewness and kurtosis found in the data.

An alternative option pricing approach has been suggested by Rubinstein (1994), Jackwerth and Rubinstein (1996) and Jackwerth (1996), and a related series of papers by Derman and Kani (1994), Dupire (1994), Chriss (1995), Derman et al. (1996). Instead of imposing a parametric functional form for volatility, they construct a binomial or trinomial numerical procedure so that a perfect fit with observed option prices is achieved. This procedure captures (by construction) the most salient characteristics of the data. In particular, the implied tree employed in the numerical estimation must correctly reproduce the volatility smile. The most popular models within this family use recombining binomial trees implied by the smile from a given set of European options.

Empirical tests of implied binomial trees have been proposed by DFW and Jackwerth (1996). DFW analyse the out-of-sample behaviour of the time-varying volatility function obtained by the in-sample implied binomial trees. The key empirical issue becomes the stability of the volatility function. Surprisingly enough, DFW find 
that the pricing (and hedging) out-of-sample performance of the implied binomial trees is worse than that of an ad hoc BS model with variable implied volatilities.

On the other hand, Jackwerth (1996) tests the pricing performance of implied binomial trees, the BS model, and the constant elasticity of variance model. He chooses the parameters of these models to fit the observed prices of longer term options best and then price shorter options with those parameters. In the 1987 post-crash period, Jackwerth favours the pricing behaviour of implied binomial trees.

Given the weak favourable evidence provided by these richer (relative to BS) models, and the empirical results of Longstaff (1995) and PRS, a serious candidate to explain the pronounced pattern of volatility estimates across exercise prices might be related with liquidity costs. In fact, after the October 1987 crash, portfolio insurers began buying index options to implement their insurance strategies. In particular, institutional investors are interested in buying out-of-the-money put options as an insurance mechanism. This institutional buying pressure on out-of-the-money put options will increase put prices to a level where market makers are induced to accept the bet that the index level will not fall below the exercise price before the option's expiration. Therefore, and independently of the distributional characteristics of the underlying asset, liquidity costs, as proxied by the relative bid-ask spread, may induce patterns in implied volatilities.

It should be pointed out that all previous models mentioned above have been developed and tested in a competitive, frictionless framework. However, as noticed above, it may certainly be the case that liquidity costs account for some of the differences observed between market prices and theoretical prices. ${ }^{1}$ Interestingly, PRS show that liquidity costs are a key determinant of the implied volatility smile in the Spanish options market.

The objective of this paper is to analyse the potential effects that illiquidity, as proxied by the relative bid-ask spread, has on option pricing. To the best of our knowledge, the only existing paper testing an option pricing model with liquidity cost is due to Ferreira et al. (1999) who study the effects of liquidity costs using a non-parametric methodology. In this paper, we propose a very different (parametric) approach. In particular, a deterministic implied volatility function along the lines suggested by DFW is employed. However, contrary to these authors, the implied volatility function is modified to incorporate the relative bid-ask spread. We solve a forward partial differential equation where, in our case, the volatility function is given by $\sigma(K, B A, T)$ where $K$ is the exercise price, $B A$ is the relative bid-ask spread and $T$ is the expiration date.

Constantinides and Zariphopoulou (1999) (and the different papers mentioned in their references) address the issue of the effect of transaction costs on option pricing from a different (theoretical) point of view. They consider an investor in an economy with bonds, stocks and a call option, and state his intertemporal consumption and investment problem in the presence of proportional transaction costs. An upper bound to the reservation write price of a call option is derived in closed form. Our objective in this paper is much more modest. We are explicitly concerned with liquidity costs. Moreover, within the (always difficult) concept of liquidity, we limit ourselves to the relative bid-ask spread.

\footnotetext{
${ }^{1}$ The issue of mispricing due to liquidity costs has been discussed by Longstaff (1995), and PRS and briefly mentioned by Eberlein et al. (1998).
} 
We employ an extensive database of intraday transaction prices for call and put options on the Spanish IBEX-35 index futures from January 1994 to October 1998. Given that we are particularly concerned with liquidity effects, it may be relevant to explore alternative option markets which are probably narrower than the fully investigated S\&P 500 index options traded at the Chicago Board Options Exchange (CBOE).

Surprisingly, liquidity costs do not seem to be a key factor in explaining the behaviour of option market prices. As DFW, an ad hoc BS pricing model performs better than our model. Of course, we assume a particular functional (parametric) relationship between volatility and liquidity costs which may well explain the failure of our option pricing model. At the same time, as fully discussed below, the instability of the parameters of our implied volatility function may also explain the poor performance of our model.

This paper is organised as follows: the next section contains a brief summary of the Spanish option market. The data are described in Section 3. The theoretical model employed in the paper appears in Section 4. Section 5 presents the empirical results regarding the out-of-sample performance of the liquidity costs-adjusted deterministic volatility function option valuation model. Finally, we conclude with a summary and discussion.

\section{The Spanish option on the IBEX-35 index futures}

Our empirical analysis focuses on the Spanish official derivative market. The IBEX-35 index is based on a portfolio composed of the 35 most liquid Spanish stocks traded in the continuous auction market system, weighted by market value. MEFF (the Spanish official derivative market for risky assets) trades a futures contract on the IBEX-35, the corresponding option (call and put) on the IBEX-35 futures contracts, and individual option contracts for blue-chip stocks. Trading in the derivative market, which started in 1992, has experienced tremendous growth from the very beginning. The volume traded in MEFF represented $40 \%$ of the volume traded in the Spanish regular continuous market in 1992 and $138 \%$ in 1996. The number of all traded contracts in MEFF relative to the contracts traded in the CBOE reached 21\% in 1996.

In this paper we are concerned with the option on the IBEX-35 index futures, which is a cash settled European option with trading during the three nearest consecutive months and the other 3 months of the March-June-September-December cycle. These options expire on the third Friday of the contract month. Daily trading takes place from 10:30 to 17:15. The multiplier has changed from 100 Spanish pesetas times the IBEX-35 index at the beginning of the sample period to 1000 pesetas during 1998 , and prices are quoted in full points, with a minimum price change of one index point. ${ }^{2}$ The exercise prices are given by 50 index point intervals. Finally, it should be noticed that liquidity is concentrated in the nearest expiration contract. In fact, during the sample period almost $90 \%$ of crossing transactions occurred in this type of contract.

\section{The data}

Our data sample includes transaction prices of all options (call and put) on the IBEX35 index futures traded daily on MEFF over the period 3 January, 1994 through 9

\footnotetext{
${ }^{2}$ Starting in January 1999 , it has been changed to 10 euros.
} 
October 1998. As noticed in the previous section, given that liquidity is concentrated in the nearest expiration contract, our daily set of observations includes only options with the nearest expiration day, but eliminating all transactions taking place during the last week before expiration. This is to say, for each monthly expiration date cycle, we only take into account prices for the first 3 weeks of the cycle.

As in the extant literature about option pricing, the use of simultaneous prices for the options and the underlying security is an issue of major concern to us. Due to the characteristics of our data, which are based on all reported transactions during each day throughout the sample period, we cannot observe simultaneously enough options on exactly the same underlying security price, with the same time-to-expiration but with different exercise prices. To avoid large variations in the underlying security price, we only take into account the 45-minute interval from 16:00 to 16:45. The number of crossing transactions during this interval is almost $25 \%$. Moreover, we eliminate from the sample all trades after 16:45 so that we avoid data which may reflect trades to influence market maker margin requirements. Therefore, we eliminate potential problems with artificial trading that are most likely to occur at the end of the day. Also, using data from the same period each day avoids the possibility of intraday effects in the IBEX-35 futures options market. Finally, all option prices that violate the well known arbitrage bounds are eliminated from the sample.

After applying these exclusionary criteria, we obtain a final daily sample of 13,056 observations (7466 transaction prices for calls and 5590 transaction prices for puts) during 1154 days. It should be noted that there are as many prices for each option per day as transactions occurred in this option during our 45-minute window. To estimate the implied volatility for each of our 13,056 transaction prices, we take as the underlying asset the average of the bid and ask price quotation given for each futures contract simultaneously observed with each transacted option during the 45-minute interval. Daily series of annualized repo T-bill rates with either 1 week, 2 weeks or 3 weeks to maturity are used as proxy for riskless interest rates. One of these three interest rates will be employed depending upon how close the option is to the expiration day. Finally, as discussed by French (1984), volatility is a phenomenon related to trading days, while interest rates are paid by the calendar day. Therefore we adjust Black's (1976) option pricing formula reflecting both trading days and calendar days until expiration. These implied volatilities will be used as the basis for constructing the deterministic volatility function.

Figure 1 presents some implied volatility functions in the volatility/strike price space for 3 representative days in our sample: the first one at the beginning of the sample (24 January 1994), the second one at the middle (11 April 1996) and the last one at the end of the sample (29 September 1998). These curves are representative of the sample period in that there is not clear evidence about the shape of the implied volatility function in the Spanish market. This is to say, on the one hand there are cases in which a quadratic function seems to fit better than a straight line (e.g., calls for 24 January 1994). On the other hand, for some other cases a straight line seems to fit better than a quadratic function (e.g., puts for 11 April 1996 and 29 September 1998). For the rest of the cases in Figure 1 (puts for 24 January 1994, calls for 11 April 1996 and calls for 29 September 1998), it is difficult to specify a priori a functional form for the implied volatility function. In any case, it seems that two functional forms are the best in capturing the shape of the implied volatility function in the Spanish market: a straight line or a quadratic function with the right-hand branch shorter than the left-hand one. 
1.1 January 24, 1994

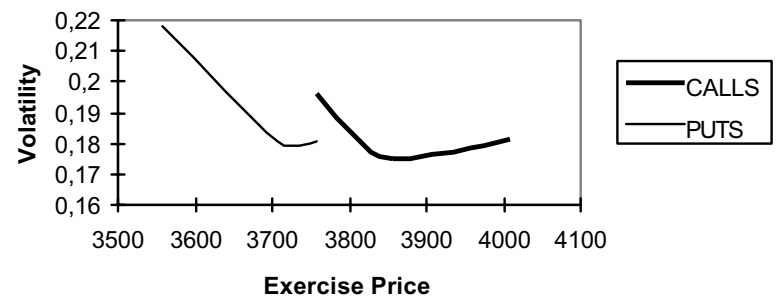

1.2 April 11, 1996

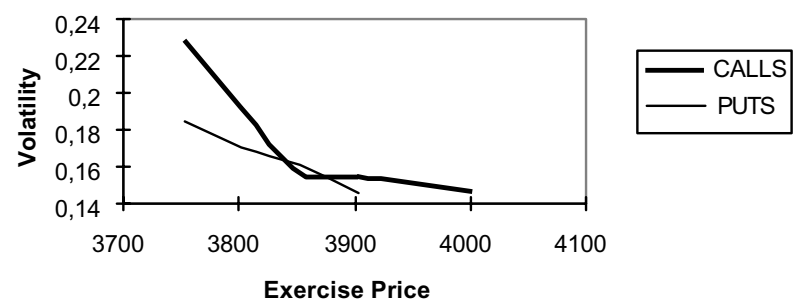

1.3 September 29, 1998

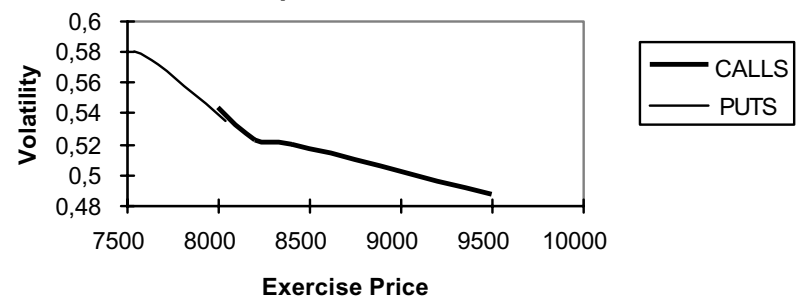

Fig. 1.

\section{Liquidity costs-adjusted deterministic volatility option valuation model}

We next theoretically investigate how liquidity costs, proxied by the relative bid-ask spread, influence option values. Given the evidence provided by DFW and PRS, we posit three different parametric forms for the deterministic volatility function $\sigma(K, T)$ :

$$
\begin{aligned}
& \text { Model 1: } \sigma=b_{0}+\varepsilon \\
& \text { Model 2: } \sigma=b_{0}+b_{1} K+\varepsilon \\
& \text { Model 3: } \sigma=b_{0}+b_{1} K+b_{2} K^{2}+\varepsilon
\end{aligned}
$$

where $\sigma$ is the implied volatility and $K$ is the exercise price. Note that in our context the general function $\sigma(K, T)$ is equal to $\sigma(K)$, because our daily set of observations includes only options with the nearest expiration day. Thus, model 1 is the volatility function of the BS constant volatility model. Model 2 posits a linear relation between 
volatility and the exercise price (the 'volatility sneer'). Finally model 3 incorporates a quadratic term to capture the typical smile shape (the 'volatility smile'). ${ }^{3}$

Given that PRS find evidence of linear Granger causality from liquidity costs to the shape of the volatility smile in the Spanish market and the theoretical arguments given in Section 1, we propose three alternative forms to introduce a linear term in the bidask spread within the deterministic volatility option pricing model:

$$
\begin{aligned}
& \text { Model 4: } \sigma=b_{0}+b_{1} B A+\varepsilon \\
& \text { Model 5: } \sigma=b_{0}+b_{1} K+b_{2} B A+\varepsilon \\
& \text { Model 6: } \sigma=b_{0}+b_{1} K+b_{2} K^{2}+b_{3} B A+\varepsilon
\end{aligned}
$$

where $B A$ is the relative bid-ask spread defined as usual as

$$
B A=\frac{\text { ask }- \text { bid }}{1 / 2(\text { ask }+ \text { bid })} .
$$

We next briefly describe the deterministic volatility function option valuation model proposed by DFW. Assuming that the local volatility rate of the underlying asset is a deterministic function of asset price and time, the option's value is given by the following partial differential equation:

$$
-\frac{1}{2} \sigma^{2}(F, t) F^{2} \frac{\partial^{2} f}{\partial F^{2}}=\frac{\partial f}{\partial t}
$$

where $F$ is the asset price for forward delivery on the expiration day of the option, $f$ is the forward option price, $\sigma(F, t)$ is the local volatility of the price $F$ and $t$ is current time. Equation (3) can be used to value both calls and puts and both European and American-style options. For a European call option the boundary condition, $f(F, T)=\max (F-K, 0), \quad$ is applied at the option's expiration $(f(F, T)=$ $\max (K-F, 0)$ for puts).

Equation (3) is called the backward equation of the BS model in terms of forward prices. Dupire (1994) shows that, for European-style options, the forward option value must be a solution of the forward partial differential equation:

$$
\frac{1}{2} \sigma^{2}(K, T) K^{2} \frac{\partial^{2} f}{\partial K^{2}}=\frac{\partial f}{\partial T}
$$

where $K$ is the exercise price and $T$ is the expiration date, with initial conditions given by $f(K, 0)=\max (F-K, 0)$ for calls and $f(K, 0)=\max (K-F, 0)$ for puts.

Let us next assume that the relative bid-ask spread is a deterministic function of exercise price and time. Hence, $B A=B A(K, T) .{ }^{4} \mathrm{~A}$ reasonable way of justifying this assumption is by checking the relationship between degree of moneyness and relative bid-ask spreads. The evidence regarding this relation is reported in Table 1. This is not a formal test, but it provides an intuitive explanation of the relationship assumed

\footnotetext{
${ }^{3}$ See PRS for a detailed discussion and tests of smiles versus sneers.

${ }^{4}$ Again note that in our context the general function $B A(K, T)$ is equal to $B A(K)$ because our daily set of observations includes only options with the nearest expiration day.
} 
Table 1

Sample characteristics of IBEX-35 futures options.

Average prices, average relative bid-ask spread and the number of available options are reported for each moneyness category. All options transacted over the 45 -minute interval from 16:00 to $16: 45$ are employed from 3 January 1994 to 9 October 1998. $K$ is the exercise price and $F$ denotes the futures price of the IBEX-35 index. Moneyness is defined as the ratio of the exercise price to the futures price. OTM, ATM, and ITM are out-of-the-money, at-the-money, and in-the-money options respectively.

\begin{tabular}{lcccr}
\hline & $\begin{array}{c}\text { Moneyness } \\
K / F\end{array}$ & $\begin{array}{c}\text { Average } \\
\text { price }\end{array}$ & $\begin{array}{c}\text { Average } \\
\text { bid-ask spread }\end{array}$ & $\begin{array}{r}\text { Number of } \\
\text { observations }\end{array}$ \\
\hline Panel A: Calls & & & & \\
Deep ITM & $0.90-0.97$ & 297.6168 & 0.1423 & 107 \\
ITM & $0.97-0.99$ & 139.5263 & 0.1283 & 551 \\
ATM & $0.99-1.01$ & 91.9031 & 0.1720 & 2312 \\
OTM & $1.01-1.03$ & 60.9031 & 0.2335 & 2336 \\
Deep OTM & $1.03-1.08$ & 43.2079 & 0.3775 & 2160 \\
All calls & - & 74.5784 & 0.2470 & \\
\hline Panel B: Puts & & & & 1927 \\
Deep OTM & $0.90-0.97$ & 46.6134 & 0.3388 & 1605 \\
OTM & $0.97-0.99$ & 66.5545 & 0.2109 & 371 \\
ATM & $0.99-1.01$ & 92.9196 & 0.1607 & 82 \\
ITM & $1.01-1.03$ & 125.6550 & 0.1267 & 5590 \\
Deep ITM & $1.03-1.08$ & 341.6585 & 0.1778 & \\
All puts & - & 75.2082 & 0.2345 & \\
\hline
\end{tabular}

above. Table 1 employs the five intervals for the degree of moneyness used by PRS and Fiorentini et al. (1998). These intervals are determined by choosing intervals of $2 \%$ length, except for the first and last intervals. 0.90 and 1.08 are the minimum and maximum values respectively for the degree of moneyness in our sample. The underlying justification in deciding these intervals is that we want a homogeneous number of observations in every interval when taking calls and puts together. We define moneyness as the ratio of the exercise price to the futures price. Deep out-ofthe-money options have the highest bid-ask spreads. This is to say, whenever the degree of moneyness is relatively high, the average bid-ask spread tends to be relatively high (low) for call (put) options.

In order to test our assumption more formally, we compute a nonparametric $\chi^{2}$ Pearson test of independence between BA and the degree of moneyness. The use of a nonparametric test may be justified by noting that we do not know the exact functional form of $B A(K)$ and, of course, by running a regression we would be imposing a given parametric form for $B A(K)$. To implement our nomparametric test we stack all observations in the same sample. Hence, we have 7466 calls and 5590 puts. The test is implemented separately for call and put options. Note that we use the degree of moneyness instead of the exercise price $(K)$ because we want to avoid the effect of different underlying asset prices corresponding to different days in the sample. It turns out that we reject the null hypothesis of independence between the relative bid-ask spread and the degree of moneyness ( $p$-value $=0.0000$ for both call 
and put options). This is to say, there is some dependence between the relative bid-ask spread and the degree of moneyness (and therefore between the relative bid-ask spread and the exercise price within our 45-minute window in a given day), but we do not know what kind of dependence exists.

Given this evidence and our assumptions, we can introduce liquidity costs within the deterministic volatility function option valuation model through the volatility factor: $\sigma^{2}(K, B A(K)$,$) . Note that we again drop the time variable, T$, since our daily set of observations includes only options with the nearest expiration day. Therefore, the forward option value with liquidity costs must be a solution of the following equation:

$$
\frac{1}{2} \sigma^{2}(K, B A(K)) K^{2} \frac{\partial^{2} f}{\partial K^{2}}=\frac{\partial f}{\partial T}
$$

with the initial condition: $f(K, B A(K))=\max (F-K, 0)$ when $T=0$ for calls, and $f(K, B A(K))=\max (K-F, 0)$ when $T=0$ for puts. Since the exact functional form of $B A(K)$ is unknown, as a first (linear) approximation to introduce the bid-ask spread within the model, we replace $\sigma(K, B A(K))$ in (5) by the expressions of $\sigma(K, B A)$ given by models 4,5 and 6 . Also, to test the simple deterministic volatility option pricing model without liquidity costs, we just replace $\sigma(K)$ in (4) by the parametric models 1,2 and 3.

\section{The empirical performance of the liquidity costs-adjusted deterministic volatility function option valuation model}

\subsection{The estimation of the model}

For each day in the sample we first estimate cross-sectionally the six parametric models given by expressions (1) and (2). In each cross-sectional regressions we employ all available options for every day from 3 January 1994 to 9 October 1998. For example, for model 6, we run the following cross-sectional regression for each day $t$ during the sample the period:

$\hat{\sigma}_{j}=b_{0}+b_{1} K_{j}+b_{2} K_{j}^{2}+b_{3} B A_{j}+\varepsilon_{j} ; \quad j=1, \ldots$, number of available options on day $t$

where $\hat{\sigma}_{j}$ is the implied volatility of option $j$ previously estimated, and $B A_{j}$ is the relative bid-ask spread for each option $j$ on each particular day in the sample period. It should be noted that these cross-sectional regressions are estimated separately for calls and puts. Equations (6) are run with 6319 observations during 755 days for call options (4246 observations during 610 days for put options). Note that we lose some observations from our original sample because our six models are run whenever there are enough observations to run model 6 .

Therefore, we obtain a daily series of cross-sectional estimators, $\hat{b}_{0 t}, \hat{b}_{1 t}, \hat{b}_{2 t}$ and $\hat{b}_{3 t}{ }^{5}$ which can be used as inputs to infer the appropriate deterministic volatility function with liquidity costs to be employed in solving equation (5). Hence, for each day $t+1$ during the sample period we estimate the following implied volatility function with

\footnotetext{
${ }^{5}$ Again note that we have a different set of estimators for calls and puts.
} 
liquidity costs:

$$
\hat{\sigma}_{j t+1}=\hat{b}_{0 t}+\hat{b}_{1 t} K_{j t+1}+\hat{b}_{2 t} K_{j t+1}^{2}+\hat{b}_{3 t} B A_{j t+1-\tau}
$$

where the exercise prices for each option $j$ are directly observed and will, in fact, coincide with exercise prices observed on day $t$. However, we need an estimate of the bid-ask spread for option $j$ on day $t+1$. For a given call (put) option, this estimate is the average of the relative bid-ask spreads for all call (put) options with the same exercise price and time to expiration, negotiated during the day $t+1$ until just before a particular transaction occurs. This period of time is called $\tau$ in equation (7). Note that each option will have a different $\tau$ depending upon its crossing time during our window from 16:00 to 16:45. Thus, for each particular call and put option available, the volatility obtained by equation (7) is employed as an input in solving the forward partial differential expression given by (5).

Therefore, using previous day out-of-sample estimators of parameters from models 1 to 6 and the estimator of the bid-ask spread described above, we can estimate expression (7) for each individual option, and then solve equation (5) to obtain the theoretical option values. Equation (5) is solved employing the Cranck-Nicholson finite-difference method. Note that this procedure allow us to test the out-of-sample performance of the option pricing model suggested in this paper under the alternative specifications of the implied volatility functions given by models 1 to 6 . The analysis of the one-step-ahead prediction errors is carried out below.

Before testing the models, however, it is important to point out that in solving our forward partial differential equation (5) we actually obtain the theoretical forward option price which will have to be discounted back to the current day in order to compare it with the market price.

\subsection{Absolute and percentage pricing errors}

We estimate models 1 to 6 , for calls and puts separately, using all call and put options available in our 45-minute window. It should be pointed out that we run these six models whenever there are enough observations to run model 6. As explained above, we then compute the theoretical price of each option using previous day estimators of parameters from models 1 to 6 and the estimator of the relative bid-ask spread described in the previous subsection.

In this way, we have 5190 (3326) pricing errors for call (put) options from 3 January 1994 to 9 October $1998 .^{6}$ These pricing errors are the basis for our analysis. Tables $2-$ 5 report two measures of performance for the alternative model specifications, and for each of our five fixed moneyness categories. Tables 2 and 3 contain the absolute pricing error for calls and puts, while the percentage pricing errors are shown in Tables 4 and 5 .

It should be noticed that we do not separate our daily sample into the five moneyness categories before estimating the models, but after estimating these models and computing theoretical prices. This is to say, we estimate our models, for call and put options separately, using all options available on day $t$, and then we compute theoretical prices for all options available on day $t+1$, using previous day estimators

\footnotetext{
${ }^{6}$ As previously noted, given that for some days we do not have enough cross-sectional options to estimate model 6 , we are forced to lose observations from our original sample.
} 
absolute pricing error: calls.

The forward partial differential equation:

$$
\frac{1}{2} \sigma^{2}(K, B A(K)) K^{2} \frac{\partial^{2} C}{\partial K^{2}}=\frac{\partial C}{\partial T}
$$

is solved replacing $\sigma^{2}(K, B A(K))$ by one of the following approximate expressions:

$$
\begin{aligned}
& \text { Model 1: } \sigma=b_{0}+\varepsilon \\
& \text { Model 2: } \sigma=b_{0}+b_{1} K+\varepsilon \\
& \text { Model 3: } \sigma=b_{0}+b_{1} K+b_{2} K^{2}+\varepsilon \\
& \text { Model 4: } \sigma=b_{0}+b_{1} B A+\varepsilon \\
& \text { Model 5: } \sigma=b_{0}+b_{1} K+b_{2} B A+\varepsilon \\
& \text { Model 6: } \sigma=b_{0}+b_{1} K+b_{2} K^{2}+b_{3} B A+\varepsilon
\end{aligned}
$$

where $K$ is the exercise price, $C$ is the option value, $b_{0}, b_{1}, b_{2}$ and $b_{3}$ are previous day estimators and $B A$ is the relative bid-ask spread. The reported absolute pricing error is the root square of the sample average of the squared difference between the model price and the market price for each call option in a given moneyness category. The statistical significance of pricing errors is assessed by means of a GMM overidentifying restrictions test to check whether the means of the series of squared differences between the model and the market prices calculated from model 1 (the BS model) and one of models 2 to 6 are significantly different. Given that we have a time

\begin{tabular}{|c|c|c|c|c|c|c|c|}
\hline & & $\mathrm{Abs}$ & olute pricis & g error: call & & & \\
\hline & Moneyness & Model 1 & $\begin{array}{c}\text { Model } 2 \\
\chi^{2} \\
\text { (p-value) }\end{array}$ & $\begin{array}{c}\text { Model } 3 \\
\chi^{2} \\
\text { (p-value) }\end{array}$ & $\begin{array}{c}\text { Model } 4 \\
\chi^{2} \\
\text { (p-value) }\end{array}$ & $\begin{array}{c}\text { Model } 5 \\
\chi^{2} \\
\text { (p-value) }\end{array}$ & $\begin{array}{c}\text { Model } 6 \\
\chi^{2} \\
\text { (p-value) }\end{array}$ \\
\hline Deep OTM & $1.03-1.08$ & 12.85 & 15.12 & 384.2307 & 40.0321 & 46.3938 & 493.8777 \\
\hline & & - & 1.1464 & 5.3145 & 1.2019 & 1.9972 & 7.1805 \\
\hline & & - & $(0.2843)$ & $(0.0211)$ & $(0.2729)$ & $(0.1576)$ & (0.0074) \\
\hline OTM & $1.01-1.03$ & 9.37 & 30.87 & 439.2902 & 63.8763 & 131.0489 & 510.6046 \\
\hline & & - & 1.1749 & 8.4520 & 1.2455 & 1.7085 & 7.3310 \\
\hline & & - & $(0.2784)$ & $(0.0036)$ & $(0.2644)$ & $(0.1612)$ & $(0.0068)$ \\
\hline ATM & $0.99-1.01$ & 10.31 & 15.89 & 553.6418 & 10.5614 & 69.3584 & 562.3090 \\
\hline & & - & 1.9825 & 4.4084 & 0.3768 & 2.0312 & 4.4896 \\
\hline & & - & $(0.1591)$ & $(0.0357)$ & $(0.5393)$ & $(0.1541)$ & $(0.0341)$ \\
\hline ITM & $0.97-0.99$ & 8.03 & 7.12 & 417.5546 & 8.8776 & 124.5359 & 585.0269 \\
\hline & & - & 1.0259 & 3.1981 & 0.4482 & 1.3877 & 3.0606 \\
\hline & & - & $(0.3113)$ & $(0.0737)$ & $(0.5032)$ & $(0.2388)$ & $(0.0802)$ \\
\hline Deep ITM & $0.90-0.97$ & 31.43 & 27.09 & 448.0721 & 31.2182 & 27.6703 & 238.7342 \\
\hline & & - & 3.2525 & 2.0796 & 0.0199 & 3.3563 & 1.1698 \\
\hline & & - & $(0.0713)$ & $(0.1493)$ & $(0.8877)$ & $(0.0669)$ & $(0.2794)$ \\
\hline All calls & - & 11.20 & 21.58 & 462.6511 & 42.8425 & 93.4947 & 525.3671 \\
\hline & & - & 1.6536 & 8.8783 & 1.9314 & 2.1876 & 10.4000 \\
\hline & & - & $(0.1985)$ & $(0.00288)$ & $(0.1646)$ & $(0.1391)$ & $(0.0013)$ \\
\hline
\end{tabular}
series of cross-sectional observations, our data are correlated and we may therefore use the Newey-West estimator for the weighting covariance matrix. The test statistic is distributed as a $\chi^{2}$ with one degree of freedom under the null. Moneyness is defined as the ratio of the exercise price to the futures price. OTM, ATM and ITM are out-of-the-money, at-the-money, and inthe-money options respectively. All call options transacted over the 45-minute interval from 16:00 to 16:45 from 3 January 1994 to 9 October 1998 are used in the tests below. 
absolute pricing error: puts.

The forward partial differential equation:

$$
\frac{1}{2} \sigma^{2}(K, B A(K)) K^{2} \frac{\partial^{2} P}{\partial K^{2}}=\frac{\partial P}{\partial T}
$$

is solved replacing $\sigma^{2}(K, B A(K))$ by one of the following approximate expressions:

$$
\begin{aligned}
& \text { Model 1: } \sigma=b_{0}+\varepsilon \\
& \text { Model 2: } \sigma=b_{0}+b_{1} K+\varepsilon \\
& \text { Model 3: } \sigma=b_{0}+b_{1} K+b_{2} K^{2}+\varepsilon \\
& \text { Model 4: } \sigma=b_{0}+b_{1} B A+\varepsilon \\
& \text { Model 5: } \sigma=b_{0}+b_{1} K+b_{2} B A+\varepsilon \\
& \text { Model 6: } \sigma=b_{0}+b_{1} K+b_{2} K^{2}+b_{3} B A+\varepsilon
\end{aligned}
$$

where $K$ is the exercise price, $P$ is the option value, $b_{0}, b_{1}, b_{2}$ and $b_{3}$ are previous day estimators and $B A$ is the relative bid-ask spread. The reported absolute pricing error is the root square of the sample average of the squared difference between the model price and the market price for each put option in a given moneyness category. The statistical significance of pricing errors is assessed by means of a GMM overidentifying restrictions test to check whether the means of the series of squared differences between the model and the market prices calculated from model 1 (the BS model) and one of models 2 to 6 are significantly different. Given that we have a time

\begin{tabular}{|c|c|c|c|c|c|c|c|}
\hline & & & solute prici & g error: put & & & \\
\hline & Moneyness & Model 1 & $\begin{array}{c}\text { Model } 2 \\
\chi^{2} \\
\text { (p-value) }\end{array}$ & $\begin{array}{c}\text { Model } 3 \\
\chi^{2} \\
\text { (p-value) }\end{array}$ & $\begin{array}{c}\text { Model } 4 \\
\chi^{2} \\
\text { (p-value) }\end{array}$ & $\begin{array}{c}\text { Model } 5 \\
\chi^{2} \\
\text { (p-value) }\end{array}$ & $\begin{array}{c}\text { Model } 6 \\
\chi^{2} \\
\text { (p-value) }\end{array}$ \\
\hline Deep ITM & $1.03-1.08$ & 18.0202 & 13.5146 & 14.5466 & 75.1225 & 21.1492 & 19.9220 \\
\hline & & - & 1.4477 & 1.1347 & 1.0372 & 0.3382 & 0.1491 \\
\hline & & - & $(0.2289)$ & $(0.2868)$ & $(0.3085)$ & $(0.5609)$ & $(0.6993)$ \\
\hline ITM & $1.01-1.03$ & 18.4131 & 148.2167 & 1119.1634 & 18.6136 & 143.9342 & 1258.3526 \\
\hline & & - & 3.8618 & 5.9551 & 0.0623 & 2.8010 & 7.9271 \\
\hline & & 一 & $(0.0494)$ & $(0.0147)$ & $(0.8028)$ & $(0.0942)$ & (0.0049) \\
\hline ATM & $0.99-1.01$ & 16.2081 & 90.0558 & 713.7516 & 16.2727 & 101.3588 & 746.1393 \\
\hline & & - & 2.2341 & 9.7662 & 0.0064 & 1.4791 & 8.3455 \\
\hline & & - & $(0.1350)$ & $(0.0017)$ & $(0.9363)$ & $(0.2239)$ & (0.0039) \\
\hline OTM & $0.97-0.99$ & 12.6136 & 61.4474 & 639.7685 & 13.7321 & 128.9690 & 661.5269 \\
\hline & & - & 3.2429 & 3.1237 & 1.5658 & 2.3144 & 9.4268 \\
\hline & & 一 & $(0.07173)$ & $(0.0771)$ & $(0.2108)$ & $(0.1281)$ & $(0.0021)$ \\
\hline Deep OTM & $0.90-0.97$ & 13.6872 & 100.5576 & 606.3112 & 21.2107 & 127.8168 & 657.2460 \\
\hline & & - & 2.6747 & 4.5443 & 7.0140 & 2.5080 & 5.3733 \\
\hline & & - & (0.1019) & $(0.0330)$ & $(0.0081)$ & $(0.1133)$ & $(0.0204)$ \\
\hline All puts & - & 14.5965 & 90.6133 & 690.6239 & 18.8247 & 121.1081 & 735.6861 \\
\hline & & - & 4.26101 & 16.6724 & 4.0108 & 4.3819 & 16.8954 \\
\hline & & - & $(0.0389)$ & $(0.0000)$ & $(0.0452)$ & $(0.0363)$ & $(0.0000)$ \\
\hline
\end{tabular}
series of cross-sectional observations, our data are correlated and we may therefore use the Newey-West estimator for the weighting covariance matrix. The test statistic is distributed as a $\chi^{2}$ with one degree of freedom under the null. Moneyness is defined as the ratio of the exercise price to the futures price. OTM, ATM and ITM are out-of-the-money, at-the-money, and inthe-money options respectively. All put options transacted over the 45-minute interval from 16:00 to 16:45 from 3 January 1994 to 9 October 1998 are used in the tests below. 
percentage pricing error: calls.

The forward partial differential equation:

$$
\frac{1}{2} \sigma^{2}(K, B A(K)) K^{2} \frac{\partial^{2} C}{\partial K^{2}}=\frac{\partial C}{\partial T}
$$

is solved replacing $\sigma^{2}(K, B A(K))$ by one of the following approximate expressions:

Model 1: $\sigma=b_{0}+\varepsilon$

Model 2: $\sigma=b_{0}+b_{1} K+\varepsilon$

Model 3: $\sigma=b_{0}+b_{1} K+b_{2} K^{2}+\varepsilon$

Model 4: $\sigma=b_{0}+b_{1} B A+\varepsilon$

Model 5: $\sigma=b_{0}+b_{1} K+b_{2} B A+\varepsilon$

Model 6: $\sigma=b_{0}+b_{1} K+b_{2} K^{2}+b_{3} B A+\varepsilon$

where $K$ is the exercise price, $C$ is the option value, $b_{0}, b_{1}, b_{2}$ and $b_{3}$ are previous day estimators and $B A$ is the relative bid-ask spread. The reported percentage pricing error is the root square of the sample average of the squared ratio of the model price minus the market price to the market price for each call option in a given moneyness category. The statistical significance of pricing errors is assessed by means of a GMM overidentifying restrictions test to check whether the means of the series of squared ratios of the model price minus the market price to the market price calculated from model 1 (the BS model) and one of models 2 to 6 are significantly different. Given that we have a time series of cross-sectional observations, our data are correlated and we may therefore use the Newey-West estimator for the weighting covariance matrix. The test statistic is distributed as a $\chi^{2}$ with one degree of freedom under the null. Moneyness is defined as the ratio of the exercise price to the futures price. OTM, ATM and ITM are out-of-the-money, at-the-money, and in-the-money options respectively. All call options transacted over the 45 -minute interval from 16:00 to $16: 45$ from 3 January 1994 to 9 October 1998 are used in the tests below.

\begin{tabular}{|c|c|c|c|c|c|c|c|}
\hline & & Perce & ntage pricir & g error: cal & & & \\
\hline & Moneyness & Model 1 & $\begin{array}{c}\text { Model } 2 \\
\chi^{2} \\
\text { (p-value) }\end{array}$ & $\begin{array}{c}\text { Model } 3 \\
\chi^{2} \\
\text { (p-value) }\end{array}$ & $\begin{array}{c}\text { Model } 4 \\
\chi^{2} \\
\text { (p-value) }\end{array}$ & $\begin{array}{c}\text { Model } 5 \\
\chi^{2} \\
\text { (p-value) }\end{array}$ & $\begin{array}{c}\text { Model } 6 \\
\chi^{2} \\
\text { (p-value) }\end{array}$ \\
\hline Deep OTM & $1.03-1.08$ & 3.3382 & 3.3712 & 30.9236 & 4.3181 & 6.0444 & 112.4591 \\
\hline & & - & 1.6210 & 4.4863 & 2.2993 & 1.1823 & 1.2405 \\
\hline & & - & $(0.2029)$ & $(0.042)$ & $(0.1294)$ & $(0.2769)$ & $(0.2654)$ \\
\hline OTM & $1.01-1.03$ & 0.3190 & 0.6126 & 12.0759 & 0.3929 & 3.9782 & 13.6184 \\
\hline & & - & 1.0751 & 9.7204 & 1.2319 & 1.5037 & 6.0183 \\
\hline & & - & $(0.2998)$ & $(0.0018)$ & $(0.2670)$ & $(0.2201)$ & $(0.0141)$ \\
\hline ATM & $0.99-1.01$ & 0.0852 & 0.1311 & 6.0218 & 0.0937 & 1.3118 & 6.6521 \\
\hline & & - & 2.2558 & 6.5112 & 12.0519 & 2.3699 & 8.7770 \\
\hline & & - & $(0.1331)$ & $(0.0107)$ & $(0.0005)$ & $(0.1237)$ & $(0.0030)$ \\
\hline ITM & $0.97-0.99$ & 0.0655 & 0.0716 & 3.8538 & 0.0684 & 1.0402 & 5.3930 \\
\hline & & - & 1.1094 & 3.0319 & 0.6529 & 1.7662 & 2.9077 \\
\hline & & - & $(0.2922)$ & $(0.0816)$ & $(0.4191)$ & $(0.1838)$ & $(0.0881)$ \\
\hline Deep ITM & $0.90-0.97$ & 0.0705 & 0.0599 & 2.6393 & 0.0682 & 0.0613 & 1.4761 \\
\hline & & - & 5.0722 & 1.8129 & 0.4715 & 4.6212 & 1.1469 \\
\hline & & - & $(0.0243)$ & $(0.1782)$ & $(0.4923)$ & $(0.0316)$ & $(0.2842)$ \\
\hline All calls & - & 1.7926 & 1.8354 & 18.2322 & 2.3174 & 4.0210 & 60.6833 \\
\hline & & - & 2.4545 & 6.5427 & 2.3349 & 2.6089 & 1.2906 \\
\hline & & - & $(0.1172)$ & $(0.0105)$ & $(0.1265)$ & $(0.1063)$ & $(0.2559)$ \\
\hline
\end{tabular}


Percentage pricing error: puts.

The forward partial differential equation:

$$
\frac{1}{2} \sigma^{2}(K, B A(K)) K^{2} \frac{\partial^{2} P}{\partial K^{2}}=\frac{\partial P}{\partial T}
$$

is solved replacing $\sigma^{2}(K, B A(K))$ by one of the following approximate expressions:

Model 1: $\sigma=b_{0}+\varepsilon$

Model 2: $\sigma=b_{0}+b_{1} K+\varepsilon$

Model 3: $\sigma=b_{0}+b_{1} K+b_{2} K^{2}+\varepsilon$

Model 4: $\sigma=b_{0}+b_{1} B A+\varepsilon$

Model 5: $\sigma=b_{0}+b_{1} K+b_{2} B A+\varepsilon$

Model 6: $\sigma=b_{0}+b_{1} K+b_{2} K^{2}+b_{3} B A+\varepsilon$

where $K$ is the exercise price, $P$ is the option value, $b_{0}, b_{1}, b_{2}$ and $b_{3}$ are previous day estimators and $B A$ is the relative bid-ask spread. The reported percentage pricing error is the root square of the sample average of the squared ratio of the model price minus the market price to the market price for each put option in a given moneyness category. The statistical significance of pricing errors is assessed by means of a GMM overidentifying restrictions test to check whether the means of the series of squared ratios of the model price minus the market price to the market price calculated from model 1 (the BS model) and one of models 2 to 6 are significantly different. Given that we have a time series of cross-sectional observations, our data are correlated and we may therefore use the Newey-West estimator for the weighting covariance matrix. The test statistic is distributed as a $\chi^{2}$ with one degree of freedom under the null. Moneyness is defined as the ratio of the exercise price to the futures price. OTM, ATM and ITM are out-of-the-money, at-the-money, and in-the-money options respectively. All put options transacted over the 45-minute interval from 16:00 to 16:45 from 3 January 1994 to 9 October 1998 are used in the tests below.

Percentage pricing error: puts

Model 1 Model 2 Model $3 \quad$ Model $4 \quad$ Model $5 \quad$ Model 6

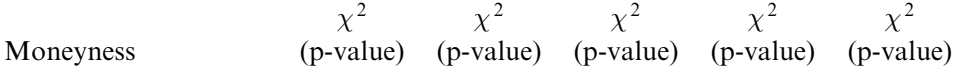

\begin{tabular}{lccccccc}
\hline Deep ITM & \multirow{2}{*}{$1.03-1.08$} & 0.0446 & 0.0340 & 0.0422 & 0.1364 & 0.0448 & 0.0487 \\
& & - & 1.8003 & 0.1037 & 1.0538 & 0.0005 & 0.2606 \\
\multirow{2}{*}{ ITM } & \multirow{2}{*}{$1.01-1.03$} & 0.0837 & $(0.1797)$ & $(0.7474)$ & $(0.3046)$ & $(0.9815)$ & $(0.6097)$ \\
& & - & 3.0539 & 5.8957 & 0.5227 & 2.4771 & 7.0692 \\
& & - & $(0.0805)$ & $(0.0152)$ & $(0.4697)$ & $(0.1155)$ & $(0.0078)$ \\
ATM & $0.99-1.01$ & 0.1451 & 1.6407 & 12.6161 & 0.1406 & 1.8276 & 14.1094 \\
& & - & 2.4142 & 6.3917 & 0.5800 & 1.5606 & 5.0435 \\
& & - & $(0.1202)$ & $(0.0115)$ & $(0.4463)$ & $(0.2116)$ & $(0.0247)$ \\
OTM & \multirow{2}{*}{$0.97-0.99$} & 0.1546 & 2.2860 & 22.9224 & 0.2506 & 4.7349 & 25.1085 \\
& & - & 2.8463 & 3.6904 & 3.2897 & 2.0887 & 2.3478 \\
& & - & $(0.0916)$ & $(0.0547)$ & $(0.0697)$ & $(0.1484)$ & $(0.1254)$ \\
Deep OTM & $0.90-0.97$ & 0.3199 & 5.7684 & 33.9285 & 0.7542 & 7.1642 & 38.0714 \\
& & - & 2.1706 & 5.2126 & 4.2811 & 1.8541 & 4.3071 \\
& & - & $(0.1407)$ & $(0.0224)$ & $(0.0385)$ & $(0.1733)$ & $(0.0379)$ \\
All calls & - & 0.2148 & 3.5899 & 23.9841 & 0.4503 & 4.8960 & 26.7326 \\
& & - & 2.8013 & 9.2266 & 4.8937 & 3.0949 & 7.1922 \\
& & - & $(0.0942)$ & $(0.0024)$ & $(0.0269)$ & $(0.0785)$ & $(0.0073)$ \\
& & & & & & &
\end{tabular}


of the parameters from models 1 to 6 and the estimator of the relative bid-ask spread described in subsection 5.1. Once we have computed these theoretical prices, we separate them into our five fixed intervals for the degree of moneyness to compute the absolute and percentage pricing errors within each category.

Imagine that, for each day $t$ in our sample, we separate all available calls (puts) within our five categories of moneyness. Now suppose that for every day, each of our five groups contains $N_{t}$ call (put) options.

The absolute pricing error is defined as:

$$
A P E=\sqrt{\frac{1}{\sum_{t=1}^{T} N_{t}} \sum_{t=1}^{T} \sum_{j=1}^{N_{t}}\left(f_{j t}^{\mathrm{TH}}-f_{j t}^{\mathrm{M}}\right)^{2}}
$$

where $f_{j t}^{\mathrm{TH}}$ is the theoretical option price for a given particular option pricing model and $f_{j t}^{\mathrm{M}}$ is the observed (market) price of the corresponding option.

The percentage pricing error is:

$$
P P E=\sqrt{\frac{1}{\sum_{t=1}^{T} N_{t}} \sum_{t=1}^{T} \sum_{j=1}^{N_{t}}\left(\frac{f_{j t}^{\mathrm{TH}}-f_{j t}^{\mathrm{M}}}{f_{j t}^{\mathrm{M}}}\right)^{2}}
$$

To compare statistically the PPE for a pair of models (say the BS model and one of models 2 to 6 ) we may compute the following set of moment conditions: ${ }^{7}$

$$
\left(\begin{array}{c}
\left(\sum_{t=1}^{T} N_{t}\right)^{-1} \sum_{t=1}^{T} \sum_{i=1}^{N_{t}}\left(\left(f_{j t}^{\mathrm{BS}}-f_{j t}^{\mathrm{M}}\right) / f_{j t}^{\mathrm{M}}\right)^{2}-\vartheta \\
\left(\sum_{t=1}^{T} N_{t}\right)^{-1} \sum_{t=1}^{T} \sum_{j=1}^{N_{t}}\left(\left(f_{j t}^{\mathrm{MO}}-f_{j t}^{\mathrm{M}}\right) / f_{j t}^{\mathrm{M}}\right)^{2}-\vartheta
\end{array}\right)=\left(\begin{array}{l}
0 \\
0
\end{array}\right)
$$

where $\vartheta$ is the common mean percentage pricing error under the null hypothesis that both models have the same percentage error, ${ }^{8}$ and $f_{j t}^{\mathrm{MO}}$ is the theoretical option price computed with one of models 2 to 6 . The idea is to perform a GMM overidentifying restrictions test to check whether the means of $\left(\left(f_{j t}^{\mathrm{TH}}-f_{j t}^{\mathrm{M}}\right) / f_{j t}^{\mathrm{M}}\right)^{2}$ calculated from a pair of model estimates are significantly different.

Given that we have a time series of cross-sectional observations, our data are correlated and we use the Newey-West estimator for the weighting covariance matrix. This test statistic is distributed as a $\chi^{2}$ with one degree of freedom under the null.

\footnotetext{
${ }^{7}$ The same procedure can be followed for the APE.

${ }^{8}$ Let $\vartheta_{1}$ be the mean of the series of squared ratios of the Black-Scholes price minus the market price to the market price: $\left(\left(f_{j t}^{\mathrm{BS}}-f_{j t}^{\mathrm{M}}\right) / f_{j t}^{\mathrm{M}}\right)^{2}$. Let $\vartheta_{2}$ be the mean of the series of squared ratios of the theoretical price calculated with one of models 2 to 6 minus the market price to the market price: $\left(\left(f_{j t}^{\mathrm{MO}}-f_{j t}^{\mathrm{M}}\right) / f_{j t}^{\mathrm{M}}\right)^{2}$. Under the null hypothesis both series have the same mean percentage error: $\vartheta_{1}=\vartheta_{2}=\vartheta$.
} 
Overall, the BS model performs better than models 2 to 6 . Only models 2 and 4 for in-the-money and deep in-the-money calls, and model 4 for in-the-money and at-themoney puts, perform as well as the BS model. In fact, model 2, which posits a linear relation between implied volatility and the exercise price, gives the second better results for call options, while model 4 , which posits a linear relation between implied volatility and the relative bid-ask spread, gives the second better results for put options. It should be pointed out that, in general, models 3 and 6 , which incorporate a quadratic term in the exercise price, value options significantly worse than the BS model. It is probably the case that the reasons behind the poor performance of the quadratic models are associated with the considerable variation in the coefficient estimates found from day to day. Note that this is consistent with the findings of DFW and might indicate that the volatility function is not stable over time. Some evidence about the instability of the parameters is presented in subsection 5.3. Another related reason behind the poor performance of the quadratic models may be associated with the collinearity between $K$ and $K^{2}$ (in fact, $K$ and $K^{2}$ are highly correlated), which can be related with the instability of parameter estimates with these quadratic models. ${ }^{9}$ Finally, recall that we assume a particular functional (parametric) relationship between volatility and liquidity costs. This may also well explain the failure of our model with bid-ask spreads.

\subsection{Proportion of theoretical prices lying outside their corresponding bid-ask spread boundaries}

In this section we report another measure of the statistical significance of performance for out-of-sample pricing errors: the proportion of theoretical prices lying outside their corresponding bid-ask spread boundaries. ${ }^{10}$

The following $Z$-statistic for the difference between two proportions is employed in the tests. The statistic is given by:

$$
Z=\frac{p_{1}-p_{2}}{\sqrt{p_{1}\left(1-p_{1}\right) / n_{1}+p_{2}\left(1-p_{2}\right) / n_{2}}}
$$

where $p_{1}$ is always the proportion of BS (model 1) prices lying outside the bid-ask spread boundaries, and $p_{2}$ is the equivalent proportion for models 2 to $6 . n_{1}$ and $n_{2}$ are sample sizes corresponding to these proportions. The statistic is asymptotically distributed as a standardized normal variable.

The results are shown in Tables 6 (calls) and 7 (puts). With this procedure we may also test whether a theoretical model undervalues or overvalues market prices. This is achieved by analysing the proportions of theoretical prices lying below the bid or above the ask quotes.

If we look at all call options together (Table 6), the proportion of BS prices lying outside the bid-ask boundaries is $45.70 \%$. This proportion is almost the same for models 2 and 4. Models 3, 5 and 6 perform significantly worse than the BS model. The proportions of BS prices lying below the bid and above the ask quotes are $18.82 \%$ and $26.88 \%$ respectively. Hence, we can conclude that the BS model tends to overvalue

\footnotetext{
${ }^{9}$ Collinarity problems between $B A$ and $K$, or between $B A$ and $K^{2}$, have not been found.

${ }^{10} \mathrm{See}$ Corrado and Su (1996) and also Fiorentini et al. (1998).
} 
Table 6

Nonparametric testing for alternative option pricing models: calls.

The forward partial differential equation:

$$
\frac{1}{2} \sigma^{2}(K, B A(K)) K^{2} \frac{\partial^{2} C}{\partial K^{2}}=\frac{\partial C}{\partial T}
$$

is solved replacing $\sigma^{2}(K, B A(K))$ by one of the following approximate expressions:

Model 1: $\sigma=b_{0}+\varepsilon$

Model 2: $\sigma=b_{0}+b_{1} K+\varepsilon$

Model 3: $\sigma=b_{0}+b_{1} K+b_{2} K^{2}+\varepsilon$

Model 4: $\sigma=b_{0}+b_{1} B A+\varepsilon$

Model 5: $\sigma=b_{0}+b_{1} K+b_{2} B A+\varepsilon$

Model 6: $\sigma=b_{0}+b_{1} K+b_{2} K^{2}+b_{3} B A+\varepsilon$

The statistical significance of performance for out-of-sample pricing errors is assessed by analysing the proportion of theoretical prices lying outside their corresponding bid-ask boundaries. The following $Z$-statistic for the difference between two proportions given by:

$$
z=\frac{p_{1}-p_{2}}{\sqrt{\frac{p_{1}\left(1-p_{1}\right)}{n_{1}}+\frac{p_{2}\left(1-p_{2}\right)}{n_{2}}}}
$$

is employed in the tests, where $p_{1}$ is always the proportion of Black-Scholes (model 1) prices outside the bid-ask boundaries, and $p_{2}$ is the equivalent proportion for models 2 to $6 . n_{1}$ and $n_{2}$ are sample sizes corresponding to these proportions. The statistic is asymptotically distributed as a standardized normal variable. All call options transacted over the 45 -minute interval from

\begin{tabular}{|c|c|c|c|c|c|c|}
\hline \multicolumn{7}{|c|}{ Proportion of model prices lying outside the bid-ask boundaries: calls } \\
\hline Categories & Model 1 & $\begin{array}{c}\text { Model } 2 \\
Z \text {-stat } \\
\text { (p-value) }\end{array}$ & $\begin{array}{c}\text { Model } 3 \\
Z \text {-stat } \\
\text { (p-value) }\end{array}$ & $\begin{array}{c}\text { Model } 4 \\
Z \text {-stat } \\
\text { (p-value) }\end{array}$ & $\begin{array}{c}\text { Model } 5 \\
Z \text {-Stat } \\
\text { (p-value) }\end{array}$ & $\begin{array}{c}\text { Model } 6 \\
Z \text {-Stat } \\
\text { (p-value) }\end{array}$ \\
\hline \multicolumn{7}{|l|}{ All calls } \\
\hline \multirow[t]{3}{*}{$p\left(\operatorname{Bid}>C_{\text {MODEL }}>\right.$ Ask $)$} & 0.4570 & 0.4470 & 0.5590 & 0.4684 & 0.4855 & 0.5930 \\
\hline & - & 1.0222 & -10.4436 & -1.1648 & -2.9146 & -14.0105 \\
\hline & - & $(0.3067)$ & $(0.0000)$ & $(0.2441)$ & $(0.0036)$ & $(0.0000)$ \\
\hline \multirow[t]{3}{*}{$p\left(C_{\text {MODEL }}<\mathrm{Bid}\right)$} & 0.1882 & 0.1676 & 0.1706 & 0.2073 & 0.2015 & 0.2146 \\
\hline & - & 2.7409 & 2.2959 & -2.4462 & -1.7160 & -3.3606 \\
\hline & - & $(0.0061)$ & $(0.0217)$ & $(0.0144)$ & $(0.0861)$ & $(0.0008)$ \\
\hline \multirow[t]{3}{*}{$p\left(C_{\text {MODEL }}>\right.$ Ask $)$} & 0.2688 & 0.2794 & 0.3881 & 0.2611 & 0.2840 & 0.3784 \\
\hline & - & -1.2087 & -13.0408 & 0.8913 & -1.7325 & -12.0185 \\
\hline & - & $(0.2267)$ & $(0.0000)$ & $(0.3727)$ & $(0.0831)$ & $(0.0000)$ \\
\hline
\end{tabular}
16:00 to 16:45 from 3 January, 1994 to 9 October, 1998 are used in the tests below. 
Table 6

Continued

Proportion of model prices lying outside the bid-ask boundaries: calls

\begin{tabular}{|c|c|c|c|c|c|c|}
\hline Categories & Model 1 & $\begin{array}{c}\text { Model } 2 \\
Z \text {-stat } \\
\text { (p-value) }\end{array}$ & $\begin{array}{c}\text { Model } 3 \\
Z \text {-stat } \\
\text { (p-value) }\end{array}$ & $\begin{array}{c}\text { Model } 4 \\
Z \text {-stat } \\
\text { (p-value) }\end{array}$ & $\begin{array}{c}\text { Model } 5 \\
Z \text {-Stat } \\
\text { (p-value) }\end{array}$ & $\begin{array}{c}\text { Model } 6 \\
Z \text {-Stat } \\
\text { (p-value) }\end{array}$ \\
\hline \multicolumn{7}{|l|}{ OTM Calls $(K / F>1)$} \\
\hline \multirow{3}{*}{$p\left(\mathrm{Bid}>C_{\mathrm{MODEL}}>\right.$ Ask $)$} & 0.4795 & 0.4702 & 0.5753 & 0.4951 & 0.5121 & 0.6079 \\
\hline & - & 0.8528 & -8.8106 & -1.4252 & -2.9802 & -11.8775 \\
\hline & - & $(0.3938)$ & $(0.0000)$ & $(0.1541)$ & $(0.0029)$ & $(0.0000)$ \\
\hline \multirow[t]{3}{*}{$p\left(C_{\mathrm{MODEL}}<\mathrm{Bid}\right)$} & 0.1741 & 0.1571 & 0.1617 & 0.2017 & 0.1916 & 0.2069 \\
\hline & - & 2.0868 & 1.5188 & -3.2275 & -2.0709 & -3.8247 \\
\hline & - & $(0.0369)$ & $(0.1288)$ & $(0.0012)$ & $(0.0384)$ & $(0.0001)$ \\
\hline \multirow[t]{3}{*}{$p\left(C_{\text {MODEL }}>\right.$ Ask $)$} & 0.3054 & 0.3131 & 0.4136 & 0.2934 & 0.3205 & 0.4010 \\
\hline & - & -0.7567 & -10.3733 & 1.1959 & -1.4859 & -9.1806 \\
\hline & - & $(0.4492)$ & $(0.0000)$ & $(0.2317)$ & $(0.1373)$ & $(0.0000)$ \\
\hline \multicolumn{7}{|l|}{ ITM Calls $(K / F<1)$} \\
\hline \multirow[t]{3}{*}{$p\left(\mathrm{Bid}>\mathrm{C}_{\mathrm{MODEL}}>\right.$ Ask $)$} & 0.3639 & 0.3511 & 0.4921 & 0.3580 & 0.3757 & 0.5325 \\
\hline & - & 0.6021 & -5.8841 & 0.2771 & -0.5523 & -7.7478 \\
\hline & - & $(0.5471)$ & $(0.0000)$ & $(0.7816)$ & $(0.5808)$ & $(0.0000)$ \\
\hline \multirow[t]{3}{*}{$p\left(C_{\mathrm{MODEL}}<\mathrm{Bid}\right)$} & 0.2456 & 0.2101 & 0.2091 & 0.2298 & 0.2416 & 0.2465 \\
\hline & - & 1.9097 & 1.9642 & 0.8368 & 0.2089 & -0.0496 \\
\hline & - & $(0.0562)$ & $(0.0495)$ & $(0.4027)$ & $(0.8345)$ & $(0.9604)$ \\
\hline \multirow[t]{3}{*}{$p\left(C_{\text {MODEL }}>\right.$ Ask $)$} & 0.1183 & 0.1410 & 0.2830 & 0.1282 & 0.1341 & 0.2860 \\
\hline & - & -1.5241 & -9.4641 & -0.6785 & -1.0731 & -9.6141 \\
\hline & - & $(0.1274)$ & $(0.0000)$ & $(0.4974)$ & $(0.2832)$ & $(0.0000)$ \\
\hline \multicolumn{7}{|c|}{ ATM Calls $(1.01>K / F \geqslant 0.99)$} \\
\hline \multirow[t]{3}{*}{$p\left(\mathrm{Bid}>C_{\mathrm{MODEL}}>\mathrm{Ask}\right)$} & 0.3858 & 0.3802 & 0.5109 & 0.3864 & 0.4057 & 0.5482 \\
\hline & - & 0.3259 & -7.1868 & -0.0369 & -1.1552 & -9.3532 \\
\hline & - & $(0.7445)$ & $(0.0000)$ & $(0.9705)$ & $(0.2480)$ & $(0.0000)$ \\
\hline \multirow[t]{3}{*}{$p\left(C_{\mathrm{MODEL}}<\mathrm{Bid}\right)$} & 0.1892 & 0.1630 & 0.1848 & 0.1904 & 0.2010 & 0.2259 \\
\hline & - & 1.9480 & 0.3187 & -0.0879 & -0.8438 & -2.5669 \\
\hline & - & $(0.0514)$ & $(0.7499)$ & $(0.9299)$ & $(0.3987)$ & $(0.0103)$ \\
\hline \multirow[t]{3}{*}{$p\left(C_{\text {MODEL }}>\right.$ Ask $)$} & 0.1966 & 0.2172 & 0.3261 & 0.1960 & 0.2047 & 0.3223 \\
\hline & - & -1.4402 & -8.4453 & 0.0416 & -0.5754 & -8.2161 \\
\hline & 一 & $(0.1498)$ & $(0.0000)$ & $(0.9668)$ & $(0.5650)$ & $(0.0000)$ \\
\hline
\end{tabular}

call options. It is interesting to note that the same tendency to overvalue call options is also found for models 2 to 6 .

When we classify all call options by moneyness, similar conclusions are obtained. This is to say, models 2 and 4 perform, in general, as well as the BS model, and models 3 and 6 (the quadratic models) perform significantly worse than the BS model. It should be pointed out that the tendency to overvalue call options is not maintained through the five categories of moneyness. All models tend to overvalue market prices for out-of-the-money calls $(K / F>1)$ and to undervalue in-the-money calls $(K / F<1)$.

Similar conclusions are obtained when we look at put options (Table 7). When we consider all put options together, the proportion of BS prices lying outside the bid-ask 
Table 7

Nonparametric testing for alternative option pricing models: puts.

The forward partial differential equation:

$$
\frac{1}{2} \sigma^{2}(K, B A(K)) K^{2} \frac{\partial^{2} P}{\partial K^{2}}=\frac{\partial P}{\partial T}
$$

is solved replacing $\sigma^{2}(K, B A(K))$ by one of the following approximate expressions:

Model 1: $\sigma=b_{0}+\varepsilon$

Model 2: $\sigma=b_{0}+b_{1} K+\varepsilon$

Model 3: $\sigma=b_{0}+b_{1} K+b_{2} K^{2}+\varepsilon$

Model 4: $\sigma=b_{0}+b_{1} B A+\varepsilon$

Model 5: $\sigma=b_{0}+b_{1} K+b_{2} B A+\varepsilon$

Model 6: $\sigma=b_{0}+b_{1} K+b_{2} K^{2}+b_{3} B A+\varepsilon$

The statistical significance of performance for out-of-sample pricing errors is assessed by analysing the proportion of theoretical prices lying outside their corresponding bid-ask boundaries. The following $Z$-statistic for the difference between two proportions given by:

$$
z=\frac{p_{1}-p_{2}}{\sqrt{\frac{p_{1}\left(1-p_{1}\right)}{n_{1}}+\frac{p_{2}\left(1-p_{2}\right)}{n_{2}}}}
$$

is employed in the tests, where $p_{1}$ is always the proportion of Black-Scholes (model 1) prices outside the bid-ask boundaries, and $p_{2}$ is the equivalent proportion for models 2 to $6 . n_{1}$ and $n_{2}$ are sample sizes corresponding to these proportions. The statistic is asymptotically distributed as a standardised normal variable. All put options transacted over the 45-minute interval from 16:00 to $16: 45$ from 3 January 1994 to 9 October 1998 are used in the tests below.

\begin{tabular}{|c|c|c|c|c|c|c|}
\hline Categories & Model 1 & $\begin{array}{c}\text { Model } 2 \\
Z \text {-stat } \\
\text { (p-value) }\end{array}$ & $\begin{array}{c}\text { Model } 3 \\
Z \text {-stat } \\
\text { (p-value) }\end{array}$ & $\begin{array}{c}\text { Model } 4 \\
Z \text {-stat } \\
\text { (p-value) }\end{array}$ & $\begin{array}{c}\text { Model } 5 \\
Z \text {-Stat } \\
\text { (p-value) }\end{array}$ & $\begin{array}{c}\text { Model } 6 \\
Z \text {-Stat } \\
\text { (p-value) }\end{array}$ \\
\hline \multicolumn{7}{|l|}{ All puts } \\
\hline \multirow[t]{3}{*}{$p\left(\mathrm{Bid}>\mathrm{C}_{\mathrm{MODEL}}>\mathrm{Ask}\right)$} & 0.5379 & 0.5177 & 0.6145 & 0.5544 & 0.5382 & 0.6584 \\
\hline & - & 1.6472 & -6.3448 & -1.3533 & -0.0232 & -10.1037 \\
\hline & 一 & $(0.0995)$ & $(0.0000)$ & $(0.1759)$ & $(0.9815)$ & $(0.0000)$ \\
\hline \multirow[t]{3}{*}{$p\left(C_{\text {MODEL }}<\mathrm{Bid}\right)$} & 0.2748 & 0.4065 & 0.3581 & 0.2724 & 0.4020 & 0.3782 \\
\hline & - & -11.4428 & -7.3323 & 0.2196 & -11.0618 & -9.0499 \\
\hline & & $(0.0000)$ & $(0.0000)$ & $(0.8262)$ & $(0.0000)$ & $(0.0000)$ \\
\hline \multirow[t]{3}{*}{$p\left(C_{\mathrm{MODEL}}>\mathrm{Ask}\right)$} & 0.2631 & 0.1112 & 0.2564 & 0.2820 & 0.1362 & 0.2802 \\
\hline & - & 0.1618 & 0.6171 & -1.7332 & 13.1122 & -1.5695 \\
\hline & - & $(0.0000)$ & $(0.5371)$ & $(0.0830)$ & $(0.0000)$ & $(0.1165)$ \\
\hline
\end{tabular}

Proportion of model prices lying outside the bid-ask boundaries: puts 
Table 7

Continued

Proportion of model prices lying outside the bid-ask boundaries: puts

\begin{tabular}{|c|c|c|c|c|c|c|}
\hline Categories & Model 1 & $\begin{array}{c}\text { Model } 2 \\
Z \text {-stat } \\
\text { (p-value) }\end{array}$ & $\begin{array}{c}\text { Model } 3 \\
Z \text {-stat } \\
\text { (p-value) }\end{array}$ & $\begin{array}{c}\text { Model } 4 \\
Z \text {-stat } \\
\text { (p-value) }\end{array}$ & $\begin{array}{c}\text { Model } 5 \\
Z \text {-Stat } \\
\text { (p-value) }\end{array}$ & $\begin{array}{c}\text { Model } 6 \\
Z \text {-Stat } \\
\text { (p-value) }\end{array}$ \\
\hline \multicolumn{7}{|l|}{ ITM Puts $(K / F>1)$} \\
\hline \multirow[t]{3}{*}{$p\left(\operatorname{Bid}>C_{\text {MODEL }}>\right.$ Ask $)$} & 0.5044 & 0.3721 & 0.5203 & 0.4691 & 0.4268 & 0.5891 \\
\hline & - & 4.5288 & -0.5351 & 1.1887 & 2.6270 & -2.8740 \\
\hline & - & $(0.0000)$ & $(0.5926)$ & $(0.2346)$ & $(0.0086)$ & $(0.0040)$ \\
\hline \multirow[t]{3}{*}{$p\left(C_{\mathrm{MODEL}}<\mathrm{Bid}\right)$} & 0.0829 & 0.1534 & 0.1323 & 0.1093 & 0.1781 & 0.2028 \\
\hline & - & -3.7014 & -2.6915 & -1.5122 & -4.8081 & -5.8568 \\
\hline & - & $(0.0002)$ & $(0.0071)$ & $(0.1305)$ & $(0.0000)$ & $(0.0000)$ \\
\hline \multirow[t]{3}{*}{$p\left(C_{\mathrm{MODEL}}>\mathrm{Ask}\right)$} & 0.4215 & 0.2187 & 0.3880 & 0.3598 & 0.2487 & 0.3862 \\
\hline & - & 7.4989 & 1.1496 & 2.1340 & 6.2707 & 1.2106 \\
\hline & 一 & $(0.0000)$ & $(0.2503)$ & $(0.0328)$ & $(0.0000)$ & $(0.2260)$ \\
\hline \multicolumn{7}{|l|}{ OTM Puts $(K / F<1)$} \\
\hline \multirow{3}{*}{$p\left(\mathrm{Bid}>\mathrm{C}_{\mathrm{MODEL}}>\mathrm{Ask}\right)$} & 0.5447 & 0.5476 & 0.6340 & 0.5719 & 0.5610 & 0.6728 \\
\hline & - & -0.2137 & -6.7628 & -2.0330 & -1.2168 & -9.8284 \\
\hline & - & $(0.8308)$ & $(0.0000)$ & $(0.0402)$ & $(0.2236)$ & $(0.0000)$ \\
\hline \multirow[t]{3}{*}{$p\left(C_{\text {MODEL }}<\mathrm{Bid}\right)$} & 0.3141 & 0.4582 & 0.4045 & 0.3057 & 0.4477 & 0.4139 \\
\hline & - & -11.1085 & -7.0231 & 0.6711 & -10.3080 & -7.7420 \\
\hline & - & $(0.0000)$ & $(0.0000)$ & $(0.5022)$ & $(0.0000)$ & $(0.0000)$ \\
\hline \multirow{4}{*}{$p\left(C_{\mathrm{MODEL}}>\mathrm{Ask}\right)$} & & 0.0893 & 0.2295 & 0.2661 & 0.1133 & 0.2589 \\
\hline & 0.2306 & 14.5744 & 0.0983 & -3.0565 & 11.6785 & -2.4436 \\
\hline & - & $(0.0000)$ & $(0.9216)$ & $(0.0022)$ & $(0.0000)$ & $(0.0145)$ \\
\hline & - & & & & & \\
\hline \multicolumn{7}{|c|}{ ATM Puts $(1.01>K / F \geqslant 0.99)$} \\
\hline \multirow[t]{3}{*}{$p\left(\operatorname{Bid}>C_{\text {MODEL }}>\right.$ Ask $)$} & 0.4971 & 0.4093 & 0.5261 & 0.5067 & 0.4266 & 0.5830 \\
\hline & - & 4.0315 & -1.3192 & -0.4359 & 3.2247 & -3.9379 \\
\hline & - & $(0.0000)$ & $(0.1871)$ & $(0.6602)$ & $(0.0013)$ & $(0.0000)$ \\
\hline \multirow[t]{3}{*}{$p\left(C_{\text {MODEL }}<\mathrm{Bid}\right)$} & 0.1120 & 0.2452 & 0.2133 & 0.1602 & 0.2432 & 0.2529 \\
\hline & - & -8.0360 & -6.3081 & -3.2092 & -7.9333 & -8.4447 \\
\hline & - & $(0.0000)$ & $(0.0000)$ & $(0.0013)$ & $(0.0000)$ & $(0.0000)$ \\
\hline \multirow[t]{3}{*}{$p\left(C_{\mathrm{MODEL}}>\right.$ Ask $)$} & 0.3851 & 0.1641 & 0.3127 & 0.3465 & 0.1834 & 0.3301 \\
\hline & - & 11.6324 & -3.4652 & 1.8242 & 10.4419 & 2.6152 \\
\hline & - & $(0.0000)$ & $(0.0005)$ & $(0.0681)$ & $(0.0000)$ & $(0.0089)$ \\
\hline
\end{tabular}

spread boundaries is $53.79 \%$. Models 2, 4 and 5 perform similarly as the BS model, since the differences between these model's proportions and the BS proportion are not significant. Once again models 3 and 6 perform significantly worse than the BS model.

If we classify all put options by moneyness, we find that all models tend to overvalue market prices for in-the-money puts $(K / F>1)$ and to undervalue out-ofthe-money puts $(K / F<1)$.

Finally, we may conclude that the tendency of all models to overvalue out-of-themoney calls and in-the-money puts and to undervalue in-the-money calls and out-ofthe-money puts is consistent with a 'sneer', rather than with a U-shaped volatility smile (or at least with a quadratic function with the right-hand branch shorter than the 
left-hand one). As pointed out in Section 3, it is interesting to observe that these two functions (the linear function and the asymmetric quadratic function) seem to be the two characteristic shapes of the implied volatility function in the Spanish market. The point is that we are not able to capture the true shape of the curve, since our models, which posit different linear relations between implied volatility and the exercise price or the bid-ask spread and quadratic relations between implied volatility and the exercise price, do not seem to improve the performance of the BS model.

On the other hand, as noticed above, the poor performance of models 2 to 6 may be associated with the considerable variation in the coefficient estimates found from day to day. Table 8 presents the mean, standard deviation and the coefficient of

Table 8

Summary statistics for parameter estimates.

The table presents the mean, the standard deviation and the coefficient of variation of parameter estimates from the following models:

$$
\begin{aligned}
\text { Model 1: } \sigma & =b_{0}+\varepsilon \\
\text { Model 4: } \sigma & =b_{0}+b_{1} B A+\varepsilon \\
\text { Model 6: } \sigma & =b_{0}+b_{1} K+b_{2} K^{2}+b_{3} B A+\varepsilon
\end{aligned}
$$

where $\sigma$ is volatility, $K$ is the exercise price and $B A$ is the relative bid-ask spread. The coefficient of variation is defined as the absolute value of the ratio of the standard deviation to the mean of the variable. This coefficient provides an adimensional measure of the variation. These models are estimated each day (whenever there are enough observations to run model 6) from 3 January 1994 to 9 October 1998, for call and put options separately. All options transacted over the 45-

\begin{tabular}{|c|c|c|c|}
\hline & & Call & Put \\
\hline \multicolumn{4}{|c|}{ Model 1: $\sigma=b_{0}+\varepsilon$} \\
\hline \multirow[t]{3}{*}{$b_{0}$} & Mean & 0.2118 & 0.2355 \\
\hline & Std. Dev. & 0.0689 & 0.0927 \\
\hline & Coef. Var. & 0.3253 & 0.3937 \\
\hline \multicolumn{4}{|c|}{ Model 4: $\sigma=b_{0}+b_{1} B A+\varepsilon$} \\
\hline \multirow[t]{3}{*}{$b_{0}$} & Mean & 0.2166 & 0.2240 \\
\hline & Std. Dev. & 0.0731 & 0.0917 \\
\hline & Coef. Var. & 0.3373 & 0.4095 \\
\hline \multirow[t]{3}{*}{$b_{1}$} & Mean & -0.0268 & 0.0625 \\
\hline & Std. Dev. & 0.0962 & 0.1986 \\
\hline & Coef. Var. & 3.5838 & 3.1754 \\
\hline \multicolumn{4}{|c|}{ Model 6: $\sigma=b_{0}+b_{1} K+b_{2} K^{2}+b_{3} B A+\varepsilon$} \\
\hline \multirow[t]{3}{*}{$b_{1}$} & Mean & -0.0038 & -0.0017 \\
\hline & Std. Dev. & 0.0828 & 0.1247 \\
\hline & Coef. Var. & 21.866 & 71.1571 \\
\hline \multirow[t]{3}{*}{$b_{2}$} & Mean & $7.873678 * 10^{-7}$ & $-4.440654^{*} 10^{-8}$ \\
\hline & Std. Dev. & $2.303259 * 10^{-5}$ & $4.7883348 * 10^{-5}$ \\
\hline & Coef. Var. & 29.2526 & 1078.3001 \\
\hline \multirow[t]{3}{*}{$b_{3}$} & Mean & 0.112253 & -0.0735 \\
\hline & Std. Dev. & 2.5054 & 3.594858 \\
\hline & Coef. Var. & 22.3197 & 48.9171 \\
\hline
\end{tabular}
minute interval from 16:00 to 16:45 are used in the estimations. There are 755 estimates for call and 610 for put options. 
variation of the parameters computed with three models (1, 4 and 6) across the 755 cross sections for call options (610 for put options). We define the coefficient of variation as the absolute value of the ratio of the standard deviation to the mean. This coefficient represents an adimensional measure of variation, which can be used to compare the degree of variation of different variables. The standard deviations and the coefficients of variation of parameters from models 4 and 6 are generally quite large, indicating that these parameters are not stable over time. ${ }^{11}$ As pointed out by DFW, if the parameter estimates are highly correlated, the errors affecting them may cancel out when looking at option prices. The correlations between the parameter estimates with model 6 are presented in Table 9. These correlations are generally not very large, except to a certain extent for put options. In any case, in general, correlations do not seem to be high enough as to cancel out the errors affecting the parameter estimates.

In summary, we may conclude that, relative to alternative deterministic option valuation models, the BS model gives the best pricing results. However, it should be noticed that linear models ( 2 and 4 ) present a very similar performance record relative to the $\mathrm{BS}$ model. In particular, it is interesting to observe how in model 4 the only variable explaining the implied volatility is the relative bid-ask spread, indicating that liquidity costs may play a certain role in explaining option prices.

Table 9

Correlations between parameter estimates.

The table presents the correlations between the parameter estimates with model 6 :

$$
\sigma=b_{0}+b_{1} K+b_{2} K^{2}+b_{3} B A+\varepsilon
$$

where $\sigma$ denotes volatility, $K$ is the exercise price and $B A$ is the relative bid-ask spread. The model is estimated each day (whenever there are enough observations) from 3 January 1994 to 9 October 1998, for call and put options separately. All options transacted over the 45-minute interval from 16:00 to 16:45 are used in the estimations. There are 755 estimates for call and 610 for put options.

\begin{tabular}{lcccc}
\hline & $b_{0}$ & $b_{1}$ & $b_{2}$ & $b_{3}$ \\
\hline Panel A: Calls & & & & \\
$b_{0}$ & 1 & -0.0785 & -0.0405 & -0.1869 \\
$b_{1}$ & 1 & -0.0070 & -0.6648 \\
$b_{2}$ & & 1 & 1 \\
$b_{3}$ & & & -0.2248 \\
Panel B: Puts & & -0.2057 & -0.1470 & -0.4150 \\
$b_{0}$ & 1 & 1 & -0.8430 & 0.3678 \\
$b_{1}$ & & & 1 & 1 \\
$b_{2}$ & & & & 0.5044 \\
$b_{3}$ & & &
\end{tabular}

\footnotetext{
${ }^{11}$ As noticed in subsection 5.2 the instability of parameter estimates with models 3 and 6 may be associated with collinearity problems between $K$ and $K^{2}$.
} 


\section{Conclusions}

To the best of our knowledge, this is one of the first papers testing an option pricing model with liquidity costs, as proxied by the relative bid-ask spread. Given the evidence provided by Longstaff (1995) and PRS, a serious candidate to explain the pronounced pattern of volatility estimates across exercise prices might be related to liquidity costs. PRS find that these costs are a key determinant of the volatility smile. We employ an extensive database of intraday transaction prices for options on the Spanish IBEX-35 index futures, from 3 January 1994 through 9 October 1998. Following DFW and PRS we posit six different models for the implied volatility as a function of exercise price and the relative bid-ask spread.

Our empirical results point out that these models do not improve the performance of the BS model. However, the role of liquidity costs cannot be completely rejected since a simple model imposing a linear relation between implied volatility and the relative bid-ask spread performs in general as well as the Black-Scholes model. We argue that the poor performance of the deterministic volatility function option valuation model (either with or without liquidity costs) might be associated with two factors. First of all, the considerable variation in the coefficient estimates found from day to day, which would indicate that the volatility function is not stable over time. As noted above, these findings are consistent with DFW. Secondly, it might be the case that we are not able to capture the true shape of the volatility smile. More research is clearly justified.

\section{References}

Aït-Sahalia, Y. and Lo, A., 'Nonparametric estimation of state-price densities implicit in financial asset prices', Journal of Finance, Vol. 53, 1998, pp. 499-547.

Bakshi, G., Cao, C. and Chen, Z., 'Empirical performance of alternative option pricing models', Journal of Finance, Vol. 52, 1997, pp. 2003-2049.

Bates, D., 'Jumps and stochastic volatility: exchange rate processes implicit in Deutsche mark options', Review of Financial Studies, Vol. 9, 1996, pp. 69-107.

Black, F., 'The pricing of commodity contracts', Journal of Financial Economics, Vol. 3, 1976, pp. $167-179$.

Black, F. and Scholes, M., 'The pricing of options and corporate liabilities', Journal of Political Economy, Vol. 81, 1973, pp. 637-659.

Burden, R. and Faires, D., Numerical Analysis (Boston: PWS, 1985).

Chernov, M. and Ghysels, E., 'What data should be used to price options?', Unpublished Manuscript, (Pennsylvania State University, 1998).

Chriss, N., 'How to grow a smiling tree', Working Paper (Harvard University, Department of Mathematics, 1995).

Constantinides, G. M. and Zariphopoulou, T., 'Bounds on prices of contingent claims in an intertemporal economy with proportional transaction costs and general preferences', Finance and Stochastics, Vol. 3, 1999, pp. 345-369.

Corrado, C. and Su, T., 'Skewness and kurtosis in S\&P 500 index returns implied by option prices', Journal of Financial Research, Vol. 19, 1996, pp. 175-192.

Das, S. and Sundaram, R., 'On smiles and smirks: a term-structure perspective', Journal of Financial and Quantitative Analysis, Vol. 34, 1999, pp. 211-239.

Derman, E. and Kani, I., 'Riding on a smile', Risk, Vol. 7, 1994, pp. 32-39.

Derman, E., Kani, I. and Chriss, N., 'Implied trinomial trees of the volatility smile', Journal of Derivatives, Vol. 3, 1996, pp. 7-22. 
Dumas, B., Fleming, J. and Whaley, R., 'Implied volatility functions: empirical tests', Journal of Finance, Vol. 53, 1998, pp. 2059-2106.

Dupire, B., 'Pricing with a smile', Risk, Vol. 7, 1994, pp. 18-20.

Eberlein, E., Keller, U. and Prause, K., 'New insights into smile, mispricing, and value at risk: The hyperbolic model', Journal of Business, Vol. 71, 1998, pp. 371-405.

Ferreira, E., Gago, M. and Rubio, G., 'A semiparametric estimation of liquidity effects on option pricing’, Working Paper (Universidad del País Vasco, Spain, 1999).

Fiorentini, G., León, A. and Rubio, G., 'Short-term options with stochastic volatility: estimation and empirical performance', Working Paper (Instituto Valenciano de Investigaciones Económicas, Spain, 1998).

French, D., 'The weekend effect on the distribution of stock prices: implications for option pricing', Journal of Financial Economics, Vol. 13, 1984, pp. 547-559.

Heston, S., 'A closed-form solution for options with stochastic volatility with applications to bond and currency options', Review of Financial Studies, Vol. 6, 1993, pp. 327-344.

Jackwerth, J. C., 'Implied binomial trees: generalizations and empirical tests', Working Paper, No. RPF-262 (University of California at Berkeley, 1996).

Jackwerth, J. C. and Rubinstein, M., 'Recovering probability distributions from option prices', Journal of Finance, Vol. 51, 1996, pp. 1611-1631.

Longstaff, F., 'Option pricing and the martingale restriction', Review of Financial Studies, Vol. 8, 1995, pp. 1091-1124.

Peña, I., Rubio, G. and Serna, G., 'Why do we smile? On the determinants of the implied volatility function', Journal of Banking and Finance, Vol. 23, 1999, pp. 1151-1179.

Rubinstein, M., 'Implied binomial trees', Journal of Finance, Vol. 49, 1994, pp. 771-818.

Taylor, S. J. and $\mathrm{Xu}, \mathrm{X}$., 'The magnitude of implied volatility smiles: theory and empirical evidence for exchange rates', Review of Futures Markets, Vol. 13, 1994, pp. 355-380. 